\title{
Biological constraints and socioecological influences on women's pursuit of risk and the sexual division of labour
}

\author{
Kathrine E. Starkweather ${ }^{1,2,3 *}$ (D), Mary K. Shenk ${ }^{4}$ and Richard McElreath ${ }^{2}$ \\ ${ }^{1}$ Department of Anthropology, University of New Mexico, Albuquerque, NM 87131, USA, ${ }^{2}$ Department of Human Behavior, \\ Ecology, and Culture, Max Planck Institute for Evolutionary Anthropology, Leipzig, Germany, ${ }^{3}$ Department of \\ Anthropology, University of Illinois Chicago, Chicago, IL, USA and ${ }^{4}$ Department of Anthropology, Pennsylvania \\ State University, State College, PA, USA \\ *Corresponding author. E-mail: kstarkweather@unm.edu
}

\begin{abstract}
Evolutionary treatments of women's work and the sexual division of labour derive from sexual selection theory and focus on an observed cross-cultural trend: tasks performed by women tend to be more compatible with childcare and produce less economic risk than tasks performed by men. Evolutionary models emphasize biological sex differences and opportunity costs to understand this pattern of behaviour, yet deviations remain poorly understood. We examine variation in women's work among Shodagor fishertraders in Bangladesh with the goal of explaining such deviations related to women's work. First, we demonstrate that women's trading produces higher variance returns than men's work - a pattern not previously quantified. Next, we test predictions from the economy of scale model to understand the socioecological circumstances associated with trading. We suggest that relaxing model assumptions around biological constraints may elucidate key circumstances under which members of one gender should systematically engage in work that is incompatible with childcare and/or produces higher levels of economic risk. Results indicate that biological sex differences are insufficient to explain gendered patterns of behaviour but removal of childcare constraints and comparative advantages related to opportunity costs can explain adherence to and deviation from trends in women's work and the division of labour.
\end{abstract}

Keywords: Sexual division of labour; parental investment; household economics; behavioural ecology

Media summary: In Bangladesh, traditionally boat-dwelling Shodagor women's trading is associated with higher economic risk than men's or women's fishing. Constraints and advantages associated with biological sex differences are important, but insufficient, to explain gendered divisions of economic and childcare labour.

\section{Introduction}

Women's engagement in high-risk economic tasks has rarely been documented empirically and is generally not discussed in evolutionary treatments of the sexual division of labour. While there is reason to expect this economic pattern is not uncommon in humans (e.g. Byrnes et al., 1999; Schubert et al., 1999; Seligmann, 2001), classic evolutionary and economic theories focus on explaining why women tend to do work that is associated with low-variance returns and is more compatible with childcare than the work that men typically do (Becker, 1985; Kaplan et al., 2000; Gurven et al., 2009; Gurven \& Hill; 2009; Bird, 1999; Bliege Bird \& Bird, 2008; Bliege Bird \& Codding, 2015). Given the importance of maternal care for and provisioning of offspring across mammalian species (Clutton-Brock, 1991),

(C) The Author(s), 2020. Published by Cambridge University Press on behalf of Evolutionary Human Sciences. This is an Open Access article, distributed under the terms of the Creative Commons Attribution-NonCommercial-ShareAlike licence (http://creativecommons.org/licenses/ by-nc-sa/4.0/), which permits non-commercial re-use, distribution, and reproduction in any medium, provided the same Creative Commons licence is included and the original work is properly cited. The written permission of Cambridge University Press must be obtained for commercial re-use. 
including humans (Hoddinott \& Haddad, 1991; Phipps \& Burton, 1998; Sear \& Mace, 2008), and the detrimental effects of high levels of variability in caloric intake for child growth and development (e.g. Gunderson \& Kreider, 2009), it is necessary to understand the full spectrum of women's economic behaviour, especially the circumstances under which women engage in economic tasks, including subsistence activities, that are not compatible with childcare and entail high levels of economic risk.

Evolutionary theory suggests that biological sex differences drive mammalian parental investment and provisioning patterns. Larger and more energetically expensive female gametes, followed by the greater post-copulatory investment of internal gestation and lactation, should favour continued parental investment by mothers under a wide variety of ecological circumstances (Trivers, 1972) unless tradeoffs with investment in existing or future offspring become steep (Hrdy, 1999). In contrast, less costly initial investment by males should result in greater allocation of energy towards gaining future mating opportunities and more variable investment in paternal care. Recent models have argued that trends in sex-specific behaviours across species may have evolved through different selective pressures. While some show that anisogamy (sex differences in gamete size) is alone sufficient for sexual selection to result in sex differences in, for example, parenting behaviours (Fromhage \& Jennions, 2016; Lehtonen et al., 2016), others indicate that ecological or demographic factors should be the driving force (Scharer et al., 2012). A recent model showed that divergence from species-typical sex roles can evolve when ecological circumstances change the costs and benefits to each sex for engaging in particular types of caregiving (Henshaw et al., 2019). Biological sex differences, including anisogamy, serve as the primary basis for current theoretical explanations of cross-cultural trends in human subsistence and parenting behaviour, but we suggest ecological and demographic factors should be taken into account when attempting to explain a wider range of gender roles in the division of labour.

The economy of scale model, a classic economic and evolutionary model of the sexual division of economic and childcare labour, assumes that the basic function of a division of labour between men and women is to enhance the efficiency of household production through complementary time allocations by mother and father (Hurtado et al., 1992; Kaplan et al., 2000; Gurven, 2004; Murdock, 1949). According to this model, women hold a 'comparative advantage' in childcare activities based on their biological abilities to gestate and lactate (Becker, 1985) and this advantage explains why women in most human societies do the majority of childcare (Konner, 2005). These 'advantages' both increase opportunity costs associated with other types of tasks (Gurven \& Hill, 2009) and may also directly motivate women to pursue economic activities that are compatible with childcare (Brown, 1970; Gurven et al., 2009; Murdock and Provost, 1973). In the interest of household efficiency, men respond to women's subsistence and childcare strategies in a complementary manner. They are free to engage in strategies that are incompatible with childcare, often pursuing resources that are associated with high levels of economic risk (e.g. Codding et al., 2011a, though see Koster, 2011 and Codding et al., 2011b for a discussion regarding this finding), require long periods of learning and skill acquisition (Kaplan et al., 2000) and provide complementary macronutrients important for child growth (Gurven et al., 2009).

In the economy of scale model, compatibility of economic activities with childcare is tied directly to gender-specific, biological constraints and advantages, but risk-proneness is not. Instead, economic risk is a byproduct of the activities men and women engage in, and not a goal (in contrast to the risk model which centres risk as an explanatory concept; Bliege Bird \& Bird, 2008). In many cases, activities that are compatible with childcare result in the acquisition of resources that provide low-risk, low-variance returns on work effort (e.g. plant foods, small game) and provide sufficient calories for family members on a daily basis (Codding et al., 2011a). As reliable access to food is necessary for child growth, development and ultimately, survival (Gunderson \& Kreider, 2009; Hawkes 1990), it is critical for at least one partner to pursue low-variance resources. This should be especially important when one partner opts to pursue resources associated with greater risk. The model would suggest, then, not that men's inherent objective is to pursue high-risk resources, but that they are free to do so, given women's pursuit of reliable, low-variance resources. This 'complementarity' of men's and women's subsistence strategies, in addition to their childcare strategies, allows parents to provide care and resources for their families in an efficient manner (Gurven et al., 2009). 
While the economy of scale model focuses on explaining trends in women's subsistence strategies, there is a great deal of variation represented across cultures. For example, although most work that women do may be more compatible with childcare than the work men do, there is a great deal of variability in absolute level of compatibility, depending on the particular task, and demographic factors like child age and intensity of childcare necessary (Hawks et al., 1997; Meehan, 2009; Panter-Brick, 1995), and women often make tradeoffs in time allocation between economic tasks and childcare, indicating that even 'traditional' subsistence tasks like foraging, horticulture, and agriculture are sometimes incompatible with childcare (e.g. Hames, 1988, 1992; Hill \& Hurtado, 1996; Ivey, 2000; Levine, 1988; Meehan, 2009). Women may also target high-energy resources (e.g. Codding, et al., 2011a), contrary to stereotypes that men (and not women) pursue 'high reward' resources. Although Codding and colleagues (2011a) show that women in some foraging societies mostly pursue high-energy resources when they come at low risk of acquisition, recent studies on women in contemporary Western societies indicate that economic risk-proneness may not differ greatly between sexes (Byrnes et al., 1999; Schubert et al., 1999) and that there may be benefits to women - as there are for men - that come from pursuing higher-risk economic strategies (Maxfield et al., 2010). Economic risk is not often quantified outside of Western or market-based societies - especially for women - but accounts of women traders in the upland Philippines suggest that trading in this context is associated with higher levels of economic risk than the work men typically engage in (Milgram, 2001), and reports of women divers in South Korea suggest that their occupation is associated with high levels of physical and economic risk (Hilty, 2015). Understanding cross-cultural trends in human behaviour is necessary, but it is also important to explain why women engage in tasks that do not adhere to such trends in order to develop models that encompass a wider range of behaviours - particularly those as critical to human societies as women's economic contributions, parenting practices and gendered divisions of labour.

This paper seeks to understand the circumstances under which women deviate from previously quantified cross-cultural trends in productive labour and engage in types of behaviour typically associated with men's work. To do this, we test predictions derived from the key assumptions of the economy of scale model. First, we broaden the model's assumptions so they apply to either gender. We thus assume that (a) constraints on and/or comparative advantages held by one gender in a particular activity and (b) complementary care for children and pursuit of risk by opposite-gendered spouses (in cases where the mother-father dyad is the primary economic unit) should explain systematic gender differences in the division of productive and reproductive labour. This leads us to predict that women should engage in tasks that produce higher levels of economic risk and are incompatible with childcare when: (a) women are not constrained by a late stage of pregnancy, breastfeeding, or care of children; (b) they have a comparative advantage in that task; and (c) their husbands are able to do work that produces low levels of economic risk and is compatible with childcare.

Here we examine differences in women's economic tasks among Shodagor fisher-traders in Bangladesh, a society in which the nuclear family is the primary economic unit and high risk of child drownings necessitates intensive care of young children. First, we model the economic risk associated with Shodagor women's and men's occupations, demonstrating that women traders produce highervariance returns than men or women who catch fish, a pattern opposite those that have been empirically demonstrated in other societies. We then compare the socioecological circumstances of women who trade with those who do not in order to test the predictions derived from the economy of scale model. We find support for a generalized economy of scale model in which removal of childcare constraints, including complementary care by fathers, and cultural and ecological comparative advantages allow many Shodagor women to engage in trading, an economically risky, childcare-incompatible task.

\section{Methods}

\section{Study population}

Shodagor people in Bangladesh are a community of traditionally nomadic, boat-dwelling fishers and traders who are culturally distinct from the primarily agricultural, settled majority ethnicity within 
Bangladesh. The Matlab area is a mostly rural subdistrict which in 2014 was home to approximately 500 Shodagor families and 230,000 majority Muslim, minority Hindu who work primarily as agriculturalists and wage labourers (ICDDRB, 2014). Branches of the Meghna River, one of the three largest and most voluminous rivers in a country containing approximately $22,155 \mathrm{~km}$ of river length across approximately 700 rivers (Ahmed \& Roy, 2007), make up the southern and northern borders of Matlab, with the confluence of the Meghna and Padma (the main distributary of the Ganges River) rivers falling just to the south of Matlab. Matlab is also bisected by the Dhonagoda River, including its streams and canals, which were home to around 150 Shodagor families in 2014. These families resided on small, wooden houseboats, clustered into groups along the rivers and in the canals, or had moved onto the land within the previous 5 years and lived in make-shift houses on the riverbanks. (See Supporting Information for more background on group demographics and ecology.)

\section{Shodagor economics}

Shodagor fisher-traders engage in a mixed subsistence and cash economy: people who catch fish sell their catch to middlemen in the markets in exchange for cash, and traders sell their goods for cash. However, in 2014, 89\% of Shodagor families in Matlab reported eating some of the fish they caught on a regular basis. Men primarily work as fishermen with $90 \%$ of the Shodagor men in Matlab fishing for at least some portion of the year in 2014. Some men also engage in day labour (11\%), selling household goods $(7 \%)$ and other types of work (2\%) throughout the year, with $18 \%$ of men reporting more than one occupation. Almost half $(44 \%)$ of Shodagor women work at least half of the year as traders, selling household goods (e.g. pots, pans, melamine products) door-to-door in villages. Some women fish with their husbands or occasionally other family members (31\%) for all or part of the year and others are primarily housewives (34\%) for at least a portion of the year. While the majority of women identify a primary occupation (and, indeed, some women engage in only one type of economic task year-round), many women switch occupations seasonally and depending on various factors, including the ages of their children (Starkweather, 2017). These economic roles differ dramatically from those of the landed Bangladeshis, among whom men are heavily engaged in agriculture and wage labour and women rarely work outside of the home (Amin 1998).

\section{Women's occupations: trading}

Trading is a physically challenging economic task: women walk miles each day with a heavy basket full of household goods carried on their heads. During the dry season (November to April) traders work long days, often beginning work before 7 a.m. and not returning home until after 7 p.m., for 6-7 days per week. They leave their homes, walk to the shops of middlemen in the market where they load up their basket with the goods they plan to sell that day (often melamine products like plates and bowls, cooking pots and utensils, jewelry or clothing), and then travel in small groups by rickshaw or CNG (small, three-wheeled compressed natural gas-powered vehicles) to villages throughout Matlab. There, they separate and walk from door to door, selling goods to non-Shodagor, Bangladeshi women. At the end of the day, women travel back to Matlab bazaar, to the middleman's shop, where they drop off the basket and unsold goods, settle their accounts, then return home. Some women also trade occasionally during the rainy season because, as one woman reported, it is difficult for households in remote villages to visit the markets, so they are more willing to purchase goods from the Shodagor women.

Only Shodagor women work as traders. Bangladeshi women who are not members of the Shodagor community do not trade because they are largely bound by cultural rules and expectations that limit the contact of women with men outside of their families and limit travel outside of their own homestead. Shodagor men only occasionally work as traders, and only do so with their wives. As the customers of traders are non-Shodagor women, the same cultural rules prevent Shodagor men from entering those women's homes unless their husbands are present. These circumstances create a 'niche' for Shodagor women to fill and provide a comparative advantage to women, as we discuss later in the paper. 
Trading is a risky occupation in multiple ways: physically, reputationally and economically. Travel by CNG can result in accidents that cause major injury or are life-threatening. As of 2014, three Shodagor women in Matlab had been involved in accidents that required major operations and/or long hospital stays. Women travelling away from home are also at risk of various types of harassment or assault by men on the streets or in villages. Shodagor women attempt to prevent this risk to physical and reputational safety by travelling in groups and interacting primarily with other women. Finally, trading poses economic risk because women may not be able to sell any of their goods on a particular day, and thus suffer a loss since they have incurred the costs of travel but not earned any money. Also, if any goods are lost, stolen or sold for a deficit, women may lose additional money. Trading also results in the occasional bonanza, for example, if a woman sells her entire basket of goods.

\section{Women's occupations: fishing}

Women who fish almost always work with their husbands, and often with children as well. Fishing is also a day-long activity, starting very early in the morning until just before sunset. There are three main types of fishing technology used by Shodagor fishers: a teta (a six-pronged spear tied to the end of a bamboo pole), borshi (hundreds or thousands of pieces of thinner fishing line with hooks on the bottom of each, tied horizontally across the width of a thicker line which is strung out across several yards of the river or canal) and fishing nets. When fishing with borshi, people typically leave home in their fishing boats by 6 a.m. to catch worms and small fish that will be used to bait each hook. They then row their boats to a particular location on the river where they will lay out the line. They wait for some amount of time before pulling up the line, removing any fish from hooks, rebaiting those hooks and then repeating the entire process. A similar process is used to fish with nets. When fishing with teta, fishers seek spots in canals where the water level is low and aim to spear larger fish as they swim by. Each adult and older child has their own spear and they spear the water repeatedly until they catch a fish. At the end of the day, fishing boats return home where adults sort the fish. Men take them to the market to sell for cash while women clean the fishing boat and prepare it for the next day.

Both borshi and fishing nets require at least two people on the boat in order to fish with maximum efficiency. One person rows the boat while the other very quickly lays down or pulls up the line or net and removes any fish or other items caught. Families report that, when husbands and wives fish together, they share these responsibilities. When they have children on the boat, mother and father also report sharing parenting duties. However, women often have additional responsibilities on the boat, such as cooking or breastfeeding infants.

\section{Women's occupations: housewife}

Housewives perform duties such as cooking, cleaning and watching young children (although most women who are not housewives also cook and clean). They do not work outside of the home and typically do not earn any income. Shodagor women work as housewives under a few different circumstances. For most women, this is a temporary state after giving birth, although the amount of time a woman waits before returning to work varies based on her previous occupation and the season of birth. Other women become housewives upon marriage. Some Shodagor families consider it 'lowstatus' if a daughter or daughter-in-law works outside the home - either because the majority of non-Shodagor Bangladeshi women (who are considered higher-status than Shodagor families) do not work outside the home or because of the risk to physical safety and reputation that comes with trading. Therefore, when arranging a marriage, the groom's family may agree that their new daughter-in-law will be a housewife. For some women, this only continues until a year or two after the birth of her first child, at which point she will begin fishing or trading. For other women, this is a permanent arrangement. This is more likely if her husband is earning enough money to support the family on his own. Occasionally, a woman will also be a housewife during the time when her children are old enough to fish with her husband but have not yet married and left home. 


\section{Data collection}

Data come from surveys conducted in 2014 with the adult members of Shodagor communities living on boats or in make-shift houses on riverbanks in Matlab, Bangladesh $(N=91)$. Here, respondents are married women, age 60 years and younger ( mean $=29.6$ years), for whom we have complete data $(N=57)$. All interviewees provided written consent. Each respondent was interviewed twice: once during the rainy season (May to October), with a follow-up interview conducted during the dry season (November to April). Surveys collected data on family demographics, income, occupations, childcare, mother's current breastfeeding status, household movement and other topics. Income data were collected in both rounds of the survey through detailed questions about total amount earned, total amount lost or paid to others and total amount netted at the end of the day for the last three days the respondent had worked.

\section{Data analysis}

Model for coefficient of variation

To demonstrate the variability of individual incomes, we estimated a coefficient of variation for each individual in the sample. The coefficient of variation $(\mathrm{CV}=$ standard deviation/mean) is a standardized measure of dispersion in a probability distribution, often used as a measure of economic risk when comparing multiple types of resources (e.g. Codding, et al., 2011a; Jones et al., 2013; Tucker et al., 2010). This means modelling each observed income using individual varying effects. Specifically, we model each individual's mean income and coefficient of variation of income in a multilevel model that pools among individuals to deal with repeat observation and imbalance in sampling. Both trading and fishing returns are reported as income in Bangladeshi taka (BDT), although when variance was calculated for fishing returns based on kilograms of fish caught, results were similar. Each individual has from 3 to 12 days of reported income, with a zero in the data indicating a day on which the individual worked but did not net any income. Each observed income $y_{-} i$ is modelled as a Gaussian variable with mean and standard deviation specific to each individual $j$ :

$$
y_{-} i \approx \operatorname{normal}\left(\mathrm{mu}_{-j}[i], \operatorname{sigma}_{-} j[i]\right)
$$

This provides a posterior distribution for each coefficient of variation $C_{-} j=\operatorname{sigma} \_j / \mathrm{mu}_{-} j$. We also included coefficients for gender and occupation, in order to assess statistical support for average differences between women and men and between fishing and trading, respectively. The complete model code and data are available on GitHub (https://github.com/kstarkweather8/EHS2020_WomenRisk).

\section{Models for behaviour}

We used a multilevel logistic regression model to test our predictions, comparing women who trade with those who do not (i.e. those who fish or are housewives). Trading was measured as a binary variable ( 1 = woman trades, 0 = woman does not trade) and is based on women's self-reports of their primary occupation. Binary predictor variables include living less than a 10 minute walk from a major market $(1 ; 0=$ living more than 45 minutes - there were no groups who live between 10 and 45 minutes from a major market), living within $5 \mathrm{~km}$ from the Meghna River as the crow flies (measured using Google Maps by drawing a straight line between the northeastern-most point of the confluence of the Dhonagoda River with the Meghna River; $0=$ lives farther than $5 \mathrm{~km}$; $1=$ lives within $5 \mathrm{~km}$ ), mother's breastfeeding status at the time of data collection $(1=$ currently breastfeeding, $0=$ not currently breastfeeding) and husband as a primary caregiver $(1,0=$ father does not act as primary caregiver for one or more months per year). Continuous predictors include the coefficient of variation produced by husband's income (estimated using the above model) and number of alloparents (mothers and fathers were asked, 'Who, besides you, have helped look after your children?'). Summary statistics are reported in Table 1 . Note that CV is included using the entire posterior distribution from the previous model, not a point estimate, in order to properly account for uncertainty. All 
Table 1. Summary statistics for predictor variables $(n=57)$

\begin{tabular}{|c|c|c|}
\hline & Trades $(n=22)$ & Does not trade $(n=35)$ \\
\hline & Mean (SD) & Mean (SD) \\
\hline Number of alloparents & $0.909(0.7502)$ & $0.371(0.5983)$ \\
\hline Husband's CV & $0.558(0.3668)$ & $0.499(0.2842)$ \\
\hline \multicolumn{3}{|l|}{ Distance to Meghna: } \\
\hline within $5 \mathrm{~km}$ & 1 & 20 \\
\hline more than $5 \mathrm{~km}$ & 21 & 15 \\
\hline \multicolumn{3}{|l|}{ Time to Market: } \\
\hline within 10 minutes & 21 & 13 \\
\hline more than 45 minutes & 1 & 22 \\
\hline \multicolumn{3}{|l|}{ Currently breastfeeding: } \\
\hline yes & 4 & 13 \\
\hline no & 18 & 22 \\
\hline \multicolumn{3}{|l|}{ Father stays home: } \\
\hline yes & 10 & 0 \\
\hline no & 12 & 35 \\
\hline
\end{tabular}

models are fit simultaneously, not sequentially, and so in principle any relationship between coefficient of variation and occupational outcomes can influence estimates of coefficient of variation.

\section{Priors}

As is common in machine learning, but less common in the sciences, we use weakly regularizing prior probability distributions for all of the regression coefficients. These priors dampen extreme effect estimates, guarding against overfitting. See McElreath (2020, chapter 7), for extensive discussion. This is especially desirable in logistic models, which often produce large and unstable estimates in the absence of prior information (see examples in McElreath, 2020, chapter 11). For the coefficient of variation model, we place weakly regularizing priors directly on the logarithm of the average income and the logarithm of the average coefficient of variation. The model turns out to be insensitive to these priors. However, placing priors instead on the mean and standard deviation can produce unstable estimates. Researchers who wish to use our approach in the future should take special note of this behaviour and the parameterization we used to address it. See McElreath (2020, chapters 13 and 14) for further discussion of the use of alternative parameterizations of statistical models.

\section{Estimation strategy}

We used adaptive Hamiltonian Monte Carlo, as implemented in Stan 2.17 (Stan Development Team, 2018) to fit these models. Models were specified through the $\mathrm{R}$ package rethinking (version 1.8, McElreath, 2020). We assessed Markov chain mixing and convergence through the R-hat criterion and an estimate of the effective number of parameters, as implemented in rstan 2.17.3. We report these statistics later, in the coefficient summary. The models mix extremely well, although this requires using a non-centred parameterization for the varying effects included in the coefficient of variation model. The exact implementation is available as $\mathrm{R}$ code in the supplement. Because these procedures produce as output a posterior distribution over the model parameters, we do not report any significance tests. Instead we focus on the magnitude and precision of estimated effects. We report $89 \%$ intervals, to avoid possible confusion with frequentist intervals. Readers should not interpret the 
inclusion of zero inside an arbitrary interval, whether 89 or 95\%, as meaningful. See McElreath (2020, chapter 3), for extensive discussion, as well as Wasserstein et al. (2019) for parallel arguments within a frequentist framework.

\section{Results}

\section{Coefficient of variation model}

Analyzing coefficient of variation as a function of occupation, fishing vs trading, supports the observation that trading is more variable than fishing (Figure 1). The posterior difference between the coefficient of variation of trading and fishing has a mean of 0.20 and an $89 \%$ credible interval from -0.01 to 0.46 . Even accounting for the occupation effect on coefficient of variation, women in the sample have higher average coefficients of variation than men, with a posterior mean difference of 0.09 (89\% credible interval -0.05-0.24). All together, an average trading woman has a coefficient of variation of income 0.31 units larger compared with an average fishing man (89\% credible interval $0.10-0.56$ ).

\section{Logistic regression models}

We use a logistic regression model to evaluate the probability that Shodagor women work as traders, an occupation that produces higher levels of economic risk (measured here using coefficients of variation) than is often associated with women's work in other cultures, rather than as fishers or housewives, occupations associated with low (or no) risk and compatibility with childcare. This model was fit simultaneously with the coefficient of variation model, so that it could make full use of the uncertainty in estimates of coefficients of variation. Figure 2 (and Table S1) provides a summary of results for this model.

As predicted, trading is associated with the removal of childcare constraints on women. Women who were breastfeeding at the time of data collection were less likely to work as traders than to fish or be housewives (posterior mean proportional odds $-1.06,89 \% \mathrm{CI}-2.15,-0.01$ ). Women who trade have more alloparents available to help watch children (posterior mean proportional odds $1.18,89 \%$ CI $0.35,2.04$ ), and women whose husbands stay home as primary caregivers of their children (posterior mean proportional odds $1.26,89 \%$ CI $0.02,2.53$ ) are more likely to trade than to do another occupation.

Women who trade are more likely to live within a 10 minute walk of a major market (posterior mean proportional odds $1.56,89 \%$ CI $0.37,2.84$ ) and are also more likely to live more than $5 \mathrm{~km}$ from the Meghna River (posterior mean proportional odds $-1.29,89 \% \mathrm{CI}-2.57,-0.02$ ) than other women. In earlier iterations of our analyses, we used multiple logistic regression models to compare among each of the three occupations. Our results from those models suggested that women who fish were more likely than other women to live within $5 \mathrm{~km}$ of the Meghna River (SI, Figure 1).

Contrary to our expectations, while complementarity of childcare does predict women's trading, complementarity of risk does not. Women who trade are equally likely to have husbands who produce low coefficients of variation in fishing as women who fish or are housewives.

\section{Discussion}

The results presented here (a) provide the first empirical demonstration of women systematically producing higher-variance economic returns than men from the same society and (b) show that the assumptions of the economy of scale model of the sexual division of labour can explain the circumstances associated with Shodagor women's trading, which produces high-variance returns and is not compatible with childcare, as well as those associated with women's occupations (fishing, housewife) that follow cross-cultural trends more closely. Results support predictions that women who trade will be unconstrained by intensive demands of childcare through weaning and alloparental care, that complementary childcare provided by fathers is critical in addition to care from alloparents and that Shodagor women's trading is associated with comparative advantages. While it is not always the 

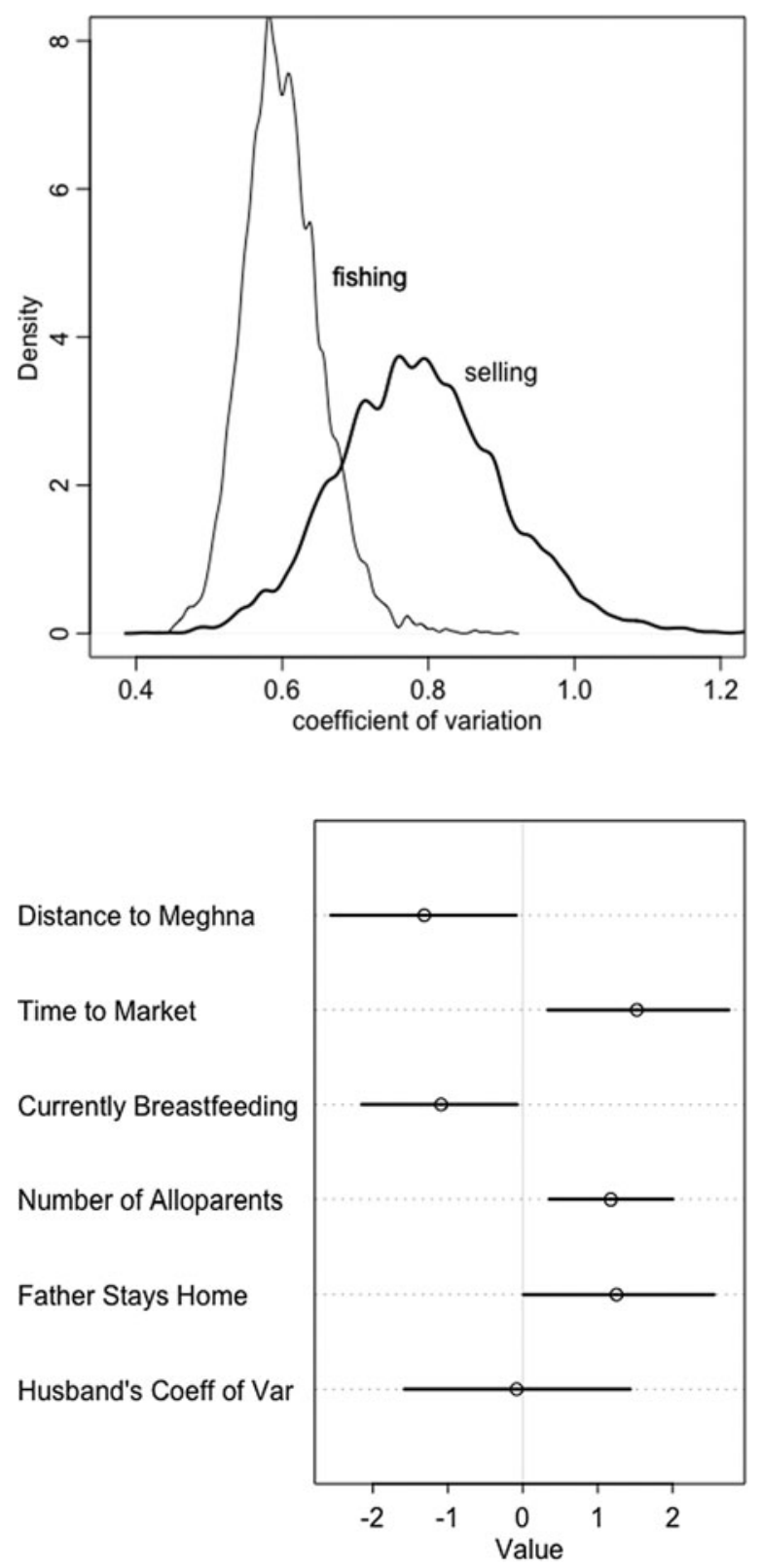

Figure 1. Full posterior distributions of coefficient of variation by occupation. Peaks represent the most probable coefficients for each curve.

Figure 2. Bayesian posterior modes and $89 \%$ credible intervals summarize 2000 retained coefficient samples, showing the relationship of each predictor variable to the outcome of woman's occupation ( 1 = trade, $0=$ does not trade) on a log-odds scale.

case that a particular occupation or subsistence strategy is incompatible with childcare and associated with high levels of economic risk, both characterize Shodagor women's trading. We discuss which of our results may be more directly related to each aspect of trading and how a more general model of the sexual division of labour may predict these aspects of women's work across societies.

\section{Removal of childcare constraints predicts trading}

Any adult who does not need to care for small children for the majority of the day is free to pursue economic or subsistence strategies that are incompatible with childcare. Weaning is a process whereby women can free themselves from the demands of suckling, and cross-cultural research shows that 
women often do so in order to return to work (Schwartz et al., 2002; Motee et al., 2013; Sellen, 2001; Levine, 1988). As predicted, our results show that, in most cases, Shodagor women whose children were fully weaned in 2014 were more likely to work as traders than to fish or be housewives. However, there is some uncertainty around the magnitude of this effect. The most likely explanation for this is that the variable used here reflects whether or not each woman was breastfeeding at all at the time of the interview, but not the frequency of suckling, which should have differential impacts on a woman's ability to trade. For example, a woman who is exclusively breastfeeding and is her child's only source of nutrition is likely to be far more constrained than one whose child only breastfeeds a few times per day and gets most of his or her nutrition from solid foods. We expect that a more detailed examination of the relationship between breastfeeding frequency and work would reveal more nuanced decision-making among women with young children. Regardless, these results indicate that the temporary constraints of intensive breastfeeding are not sufficient to keep women from ever participating in economic tasks that are incompatible with childcare.

In addition to weaning, a mother must also have alternative caregivers available to watch her children while she works. Alternative caregivers are also a necessity for fathers to engage in childcare-incompatible economic tasks, but the economy of scale model assumes that maternal care fills this need. Thus, we predicted, and the data show, that complementary care from a spouse is an important predictor of Shodagor women's trading. Instead of fishing or earning money as day labourers, some fathers stay at home during the dry season to be primary caregiver for young children while their wives are working. Although the amount of paternal care among Shodagor households has not yet been formally quantified, women who trade often work 5-7 days per week for 8-10 hours per day and fathers who care for children during this time report engaging in childcare the majority of the day. Compared with cross-cultural reports of paternal care, these Shodagor men appear to be at the very high end of time spent with children (Marlowe, 2000).

While there may be more cases of systematically high levels of paternal care than are quantified or represented in the behavioural ecology literature (e.g. Livingston, 2014; Milgram, 2001; OECD, 2017), the overwhelming cross-cultural norm for paternal care appears to be one of low direct investment relative to mothers. For Shodagor families, high rates of paternal care probably represent a behavioural adaptation to a unique ecology, which includes a high risk of drowning for young children. Among the majority population in Matlab, $40 \%$ of deaths of children between the ages of 1 and 4 years were due to drowning in 2016 (ICDDRB, 2016). A nationwide study from 2003 shows an even higher rate of death for that age group (Rahman et al., 2009). Over 35\% of children who drowned did not have a specified caregiver, and of those who did, $52 \%$ had caregivers who were under the age of 15 . In contrast, in qualitative interviews, Shodagor adults report that child drowning is not a major cause of child death in their communities, which suggests that their caregiving strategies are effective. Under different socioecological circumstances, we might see that women do childcare-incompatible work when they have older children who are able to be left at home with minimal supervision (e.g. Starkweather, 2017) or when alloparents can substitute the majority of daily care for younger children (e.g. Ivey, 1993; 2000; Meehan, 2008; Quinlan, 2003). In both cases, we would still expect time spent in childcare by mothers and fathers to be somewhat complementary in that fathers should increase the amount of direct care to make up for lost care by mothers, as has been shown among Aka fathers (Hewlett, 1991).

While complementary care from a spouse is important in this case study, we also expect alloparents to play a role in allowing women to do work that is not compatible with childcare. The reality for most families in most societies - even when the mother is the primary caregiver of children - is that children are cared for by a constellation of different people, including mothers, fathers and alloparents (Meehan et al., 2016). Indeed, our results show that having more alloparents available increased the likelihood that a woman would trade. The independent importance of fathers and alloparents suggests that both are key in allowing women to trade and indicates three possible caretaking scenarios: (a) either one type of caregiver or the other (fathers or alloparents) is doing the vast majority of care; (b) fathers and alloparents work together to create a patchwork of daily caregivers for children; or (c) one type of caregiver provides daily care for younger children and another for older children. Shodagor 
families probably represent a combination of these scenarios. Among Agta families, when mothers are engaged in other activities, alloparents appear to do the majority of intensive childcare (e.g. holding) and fathers do less-intensive types of care (e.g. watching, proximity; Page et al., 2019). Some Shodagor trading families display a similar pattern but with fathers doing the bulk of daily care and alloparents providing supplementary care. The choice of caregiver(s) and the amount of time dedicated to caretaking by fathers and alloparents probably varies over time and between families depending on multiple factors that include a household's economic need, alloparents' alternative commitments (e.g. work, caring for other children) and child age.

\section{Ecological and cultural comparative advantages in trading}

While weaning and allomaternal care providers allow women to engage in economic tasks that are not compatible with childcare, they may not be sufficient to explain women's engagement in a high-risk economic activity. The economy of scale model, as originally written (Becker, 1985), suggests that men's pursuit of risky economic tasks is a byproduct of the complementary nature of their work, which is a response to women's comparative advantages in childcare. Gurven and colleagues (2009) later suggested that opportunity costs associated with particular activities should also play a role in risk pursuit. We suggest that, rather than risk being a byproduct of work that is incompatible with childcare, comparative advantages in a high-risk task, which take opportunity cost into account, and the complementary pursuit of low-risk resources by a spouse, should allow individuals of one gender to systematically engage in the high-risk task.

The economy of scale model focuses on the comparative advantage that women are afforded by their biological ability to gestate and lactate, but we should expect comparative advantages to stem from other sources, too, including the local socioecology. Ecological settings influence selective pressures on sex differences among various species in provisioning and direct parental investment (Scharer et al., 2012). The local ecology also influences the resources that are available for human use, as well as seasonal availability of and opportunity costs associated with different resources. Seasonality (Marlowe, 2007) and energy/risk tradeoff (Codding, et al., 2011a) associated with resources that are available in certain ecologies may also affect how labour is divided by gender. Our data show that important aspects of the Shodagor ecology - distance to a major market and distance to the Meghna River - distinguish among the primary occupations women choose to pursue. Women are more likely to trade if they live closer to a major market and farther from the Meghna River. Each of these ecological features represents different opportunity costs for women. Living near a market reduces the amount of travel time between home and the middleman's shop, which traders visit in the morning to pick up their basket and in the evening to drop it off. Living farther from the Meghna River increases costs to fishing especially during the dry season when fish are less abundant farther from the Meghna. Earlier analyses also showed that women who fish were more likely to live near the Meghna, where fishing is profitable year-round (Islam \& Chuenpagdee, 2018; Figure S1). These results indicate that women are sensitive to opportunity costs associated with local ecological features when choosing an occupation. They also suggest that comparative advantage in a risky activity may be born from opportunity costs, as predicted by Gurven and colleagues (2009), but that factors beyond biological sex differences should be considered in order to understand gender differences in pursuit of economic risk.

Of course, Shodagor men - in fact, everyone living in Matlab - should be sensitive to the same costs and benefits. However, comparative advantage in an activity associated with high economic risk may also be associated with aspects of culture. Zapotec women traders primarily sell products to other women in marketplaces, operating within an economic sphere open exclusively to women by custom (Chinas, 2002). Similarly, haenyeo women divers in South Korea reportedly took over diving tasks from men in the seventeenth century because women's wages were not subject to taxation (Hilty, 2015). Likewise, Shodagor women traders report a comparative advantage over men and over non-Shodagor women related to cultural rules and expectations of the majority Muslim population in Bangladesh. The majority of rural Bangladeshi women who are not Shodagor follow rules of 
seclusion, or purdah (Amin, 1997), which limits the contact of women with men outside of their families, while most Shodagor women do not follow these rules. It is thus culturally acceptable for non-Shodagor women to interact with other women, even without a male relative present, but it is not acceptable for them to interact in the same way with an unknown or unrelated man. Shodagor women report that this allows them to fill a niche as traders, trading door-to-door to women in remote villages who rarely have the opportunity to visit the market, whereas men (whether Shodagor or not) would be unable to fill this role.

In short, ecological and cultural comparative advantages in Bangladesh converge to create a niche only available for a subset of Shodagor women to fill. The occupation associated with the niche produces high levels of economic risk. Although we expect comparative advantages to be contextdependent, our results show that they need not be based exclusively on biological sex differences in order to explain a wide range of divisions of labour by gender.

\section{Complementary risk strategies}

High levels of variance in nutrient and caloric intake can be detrimental for children's health and wellbeing (e.g. Cook et al., 2004; Gundersen \& Kreider, 2009; Gundersen \& Ziliak, 2015), therefore, we expect parents to provide children with reliable calories as often as possible. The economy of scale model suggests that when resources are pooled at the household level, higher-variance returns - usually pursued by fathers, which may also provide complimentary nutrients - are offset by mothers' provisioning of reliable resources, and work together to support child health and well-being (Gurven et al., 2009). Therefore, we expected that Shodagor women's higher-variance returns from trading would be offset by husbands' reliable fishing returns. Our model results do not formally support this prediction: men's economic risk (CV) does not differ based on wife's occupation (Figure 2). However, our results also do not necessarily contradict our prediction. In fact, we show that the fishing methods used by all Shodagor people produce relatively reliable, low-variance returns (Figure 1), so there may be little difference between husbands based on wife's occupation simply because there is little variation in returns to this occupation in general.

When considering the potential for complementarity in risk strategies between spouses, it is also necessary to take into account tradeoffs associated with market integration. While over $80 \%$ of Shodagor households engage in subsistence fishing occasionally, a large majority of fish are sold in markets in exchange for the local currency, BDT. Traders also exchange goods for cash. Unlike the resources acquired in 'immediate-return' systems experienced in some foraging societies (e.g. Woodburn, 1982), money is 'both storable and fungible' (Gurven et al., 2015), meaning it can be saved and used at a later date to buffer against future resource shortfalls. It is likely that excess income earned by traders (i.e. income not used the same day it was earned) is saved and later spent on days when not enough is earned to cover the household's expenditures. Indeed, high-mean returns on trading would also alter tradeoffs associated with higher variance (Jones et al., 2013). However, our model shows that trading is associated with a lower average daily income than fishing (Figure S2), and raw data indicate that traders earned an average of 262 BDT per day in 2014 (the equivalent of around 3.00 USD), while fishers earned an average of $652 \mathrm{BDT}$ per day (approximately $7.70 \mathrm{USD}$ ). This suggests that traders are much less likely than fishers to have excess income at the end of the day and therefore less likely to use their own income to buffer against later shortfalls. Instead, multiple Shodagor families report saving fishing income from the rainy season to use during the dry season, indicating that modelling a husband's economic risk-taking may not be sufficient to understand complementarity in spousal risk strategies, nor economic motivations underlying Shodagor women traders' pursuit of a high-risk occupation. Future research will examine the cross-seasonal nature of risk buffering in Shodagor households, including the impact of a husband's (or husband and wivfe's joint) rainy season earnings on a wife's dry season economic risk-taking.

In Shodagor trading households, the possible excess of a storable resource (i.e. money) produced by men's fishing should be critical in shaping women's risk sensitivity primarily because fishing and 
trading are done during opposite seasons. We expect the low-variance nature of fishing to be important during the rainy season when the majority of household resources are a product of fishing, but the ability to save money to buffer against women's risk-taking may be critical during the dry season. In other cultural contexts, when occupations switch seasonally and in a manner similar to what Shodagor families experience, we expect women's sensitivity to variance to be structured according to access storable resources saved from previous seasons. However, for contexts in which men and women engage in occupations with different risk profiles at the same time, women's pursuit of variance should be related to men producing lower-variance resources and not to men producing an excess of resources, or the storability of those resources. Overall, these results suggest that, in contexts where men's primary occupation is associated with low-variance returns, and possibly also when it produces an excess of storable resources (e.g. money), women could be in a strong position to pursue higher-risk tasks when ecological and cultural circumstances allow.

\section{Limitations}

This study has a few limitations. First, while we show support for predictions based on the economy of scale model, we do not have the data necessary to adequately test the ability of other models of sex- or gender-role specialization to explain the variety of gendered labour patterns among Shodagor families (e.g. Bliege Bird \& Bird, 2008; Fromhage \& Jennions, 2016; Henshaw et al., 2019; Lehtonen et al., 2016; McNamara et al., 2000). Future work will explore possible alternative explanations for Shodagor gendered division of labour, including effect of sex ratio or mating competition, and evidence of social benefits from trading.

Second, the cross-sectional nature of this dataset makes it difficult to determine the direction of causality between a woman's occupation and her socioecological circumstances. While we would expect most of the variables we measure to adjust in real time to a woman's occupation (e.g. a man could adjust his economic risk-seeking to meet his wife's), ecological variables are more difficult to interpret in this respect. We do not know if a family chose their location based on a woman's occupation, or if she chose her occupation in response to the location of her family's residence. The mobility of boat-dwelling families further complicates interpretation, as mobility should allow households to change locations in order for women to engage in a particular occupation. However, self-selection into ecological circumstances associated with lower opportunity costs for an economic task does not negate the importance of the comparative advantage women experience. There is also little evidence from other data collected in 2014 to suggest that many families are moving in order for women to change occupations. So, despite potentially confounding factors of cross-sectional data and mobile households, we suggest that ecological comparative advantages provide a proximate explanation for Shodagor women's occupational decisions.

\section{Conclusions}

Weaned children, alloparental care, complimentary paternal care, ecological and cultural comparative advantages in trading, and potentially complementary low-variance subsistence work by husbands, are all associated with Shodagor women's trading. Given the cross-sectional nature of this data, we are unable to determine causal relationships between these variables, however, they support our predictions based on the assumptions of the economy of scale model of the human division of labour by gender. Other models of the division of labour suggest different mechanisms by which gendered divisions of labour may have evolved. For instance, in the risk model, economic risk is a strategy employed by men in order to gain social status and future mating opportunities (Bliege Bird and Bird, 2008). Based on our findings, we suggest that in societies in which monogamous marriage is the overwhelming social norm, probably as a functional response to socioecology (e.g. Schacht and Borgerhoff Mulder, 2015; Schacht and Kramer, 2016), and childcare and household economics are largely concentrated within the nuclear family - both of which are true in Shodagor communities 
(Starkweather, 2017) - the economy of scale model may be well suited to understanding the factors that influence how men and women divide economic and childcare labour. Future studies should examine longitudinal change in socioecological circumstances and their relationship to women's occupations, as well as differences between women and within the same women over time in order to understand how these and other factors may influence individual risk preferences among traders.

Women's economic contributions to the household have implications for the growth, health and well-being of children across cultures and subsistence systems. Despite the focus of current evolutionary models of gendered divisions of labour on trends in women's work - usually based on patterns observed in modern foraging communities - women around the world perform economic tasks that vary in the degree to which they are compatible with childcare and the amount of economic risk entailed. In order to develop theoretical models that represent the full range of women's (and men's) behaviour, and its impact on divisions of labour within a society, it is necessary to understand the conditions that lead to differences in these behaviours between and within societies. In this case study of one community in which women's occupations represent adherence to and deviation from cross-cultural trends in women's work, we provide one of the first empirical demonstrations of a society in which nearly half of all women engage in an occupation that produces higher levels of economic risk than men's primary occupation, and we show that broadening the assumptions of the economy of scale model to apply to parents of any gender can lead to accurate predictions of the socioecological circumstances associated with different occupations. These results indicate that, contrary to evolutionary models that centre explanations of gendered divisions of labour around biological sex differences, constraints of lactation and childcare need not relegate women to specific kinds of work. Finally, these results also challenge the notion that biological sex differences primarily drive women's pursuit of lowrisk activities and instead implicate ecological and cultural circumstances as a suite of factors that affect women's decision-making around the economic strategies they will employ. Much more empirical research on women's work, including quantification of economic risk, across different types of societies is necessary to understand variation in women's economic behaviour and to fully flesh out the evolutionary implications of this behaviour.

Supplementary material. To view supplementary material for this article, please visit https://oi.org/10.1017/ehs.2020.60

Acknowledgements. The authors would like to thank the Shodagor communities in Matlab, Bangladesh for their participation in this project, as well as their generosity, kindness, and friendship. We would also like to thank Fatema tuz Zohora and Siddiqudzaman for their assistance with data collection and various other tasks in the field. We thank Dr Nurul Alam, Taslim Ali and the HDSS staff at ICDDRB in both Matlab and Dhaka for providing logistical support.

Author contributions. KS and MS designed and developed the study. KS collected the data used in this study. RM and KS analyzed the data. All authors assisted in drafting and revising the manuscript.

Financial support. This work was supported by the Wenner-Gren Foundation (grant no. 8578).

Conflicts of interests. All authors declare they have no conflicts of interest.

Data availability statement. Data and code in $\mathrm{R}$ to reproduce the analysis in the main text are available on Github at https://github.com/kstarkweather8/EHS2020_WomenRisk.

\section{References}

Ahmed, A. M. M. M., \& Roy, K. (2007). Utilization and conservation of water resources in Bangladesh. Journal of Developments in Sustainable Agriculture, 2, 35-44.

Amin, S. (1997). The poverty-purdah trap in rural Bangladesh: Implications for women's roles in the family. Development and Change, 28(2), 213-233.

Amin, S. (1998). Family Structure and Change in Rural Bangladesh. Population Studies, 52(2), 201-213.

Becker, G. S. (1985). Human capital, effort, and the sexual division of labor. Journal of Labor Economics, 3(1), S33-S58. Bird, R. (1999). Cooperation and conflict: The behavioral ecology of the sexual division of labor. Evolutionary Anthropology, 8 (2), 65-75. 
Bliege Bird, R., \& Bird, D. W. (2008). Why women hunt: Risk and contemporary foraging in a western desert Aboriginal community. Current Anthropology, 49(4), 655-693.

Bliege Bird, R., \& Codding, B. F. (2015). The sexual division of labor. In R. A. Scott \& S. M. Kosslyn (Eds.), Emerging trends in the social and behavioral sciences (pp. 1-16). John Wiley \& Sons.

Brown, J. (1970). A note on the division of labor by sex. American Anthropologist, 72, 1073-1078.

Byrnes, J. P., Miller, D. C., \& Schafer, W. D. (1999). Gender differences in risk taking: A meta-analysis. Psychological Bulletin, 125(3), 367-383.

Chinas, B. N. (2002). The Isthmus Zapotecs: A matrifocal culture of Mexico. Cengage Learning.

Clutton-Brock, T. (1991). The evolution of paternal care. Princeton University Press.

Codding, B. F., Bliege Bird, R., \& Bird, D. W. (2011a). Provisioning offspring and others: Risk-energy trade-offs and gender differences in hunter-gatherer foraging strategies. Prodeedings of the Royal Society B: Biological Sciences, 278(1717), 2502-2509.

Codding, B. F., Bliege Bird, R., \& Bird, D. W. (2011b). Women, men, risk and energy: A reply to Koster's paradox of Ache foraging. Prodeedings of the Royal Society B: Biological Sciences, 278, 3173-3174.

Cook, J. T., Frank, D. A., Berkowitz, C., Black, M. M., Casey, P. H., Cutts, D. B., ... Nord, M. (2004). Food insecurity is associated with adverse health outcomes among human infants and toddlers. The Journal of Nutrition, 134(6), 1432-1438.

Fromhage, L., \& Jennions, M. D. (2016). Coevolution of parental investment and sexually selected traits drives sex-role divergence. Nature Communications, 7, 12517.

Gundersen, C., \& Kreider, B. (2009). Bounding the effects of food insecurity on children's health outcomes. Journal of Health Economics, 28, 971-983.

Gundersen, C., \& Ziliak, J. P. (2015). Food insecurity and health outcomes. Health Affairs, 34, 1830-1839.

Gurven, M. (2004). To give and to give not: The behavioral ecology of human food transfers. Behavioural and Brain Sciences, $27,543-583$.

Gurven, M., \& Hill, K. (2009). Why do men hunt? A reevaluation of 'Man the Hunter' and the sexual division of labor. Current Anthropology, 50(1), 51-74.

Gurven, M., Jaeggi, A. V., von Rueden, C., Hooper, P. L., \& Kaplan, H. (2015). Does market integration buffer risk, erode traditional sharing practices and increase inequality? A test among Bolivian forager-farmers. Human Ecology, 43, 515-530.

Gurven, M., Winking, J., Kaplan, H. S., von Rueden, C., \& McAllister, L. (2009). A bioeconomic approach to marriage and the sexual division of labor. Human Nature, 20(2), 151-183.

Hames, R. B. (1988). The allocation of parental care among the Ye'kwana. In L. Betzig, M. Borgerhoff Mulder, \& P. Turke (Eds.), Human reproductive behavior (pp. 237-252). Cambridge University Press.

Hames, R. B. (1992). Variation in paternal care among the Yanomamo. In B. Hewlett (Ed.), Father-child relations: Cultural and biosocial contexts (pp. 85-110). Aldine de Gruyter.

Hawkes, K. (1990). Why do men hunt? Benefits for risky choices. In E. Cashdan (Ed.), Risk and uncertainty in tribal and peasant economies (pp. 145-166). Taylor \& Francis.

Hawkes, K., O'Connell, J. F., \& Blurton Jones, N. G. (1997). Hadza women's time allocation, offspring provisioning, and the evolution of long postmenopausal life spans. Current Anthropology, 38(4), 551-577.

Henshaw, J. M., Fromhage, L., \& Jones, A. G. (2019). Sex roles and the evolution of parental care specialization. Prodeedings of the Royal Society B: Biological Sciences, 286, 20191312.

Hewlett, B. (1991). Demography and childcare in preindustrial societies. Journal of Anthropological Research, 47(1), 1-37.

Hill, K., \& Hurdado, A. M. (1996). Ache life history: The ecology and demography of a foraging people. Routledge.

Hilty, A. (2015). Jeju Haenyeo: Stewards of the sea (Vol. 1). Jeju National University.

Hoddinott, J., \& Haddad, L. (1991). Household expenditures, child anthropometric status, and the intrahousehold division of income: Evidence from the Cote d'Ivoire. Research Program in Development Studies. Presented at the Woodrow Wilson School, Princeton University.

Hrdy, S. (1999). Mother Nature: A history of mothers, infants, and natural selection. Pantheon.

Hurdado, A. M., Hill, K., Kaplan, H. S., \& Hurtado, I. (1992). Tradeoffs between female and food acquisition and child care among Hiwi and Ache foragers. Human Nature, 3, 185-216.

ICDDRB (2014). Health and demographic surveillance system - Matlab: Annual report (Scientific Report no. 103). ICDDRB.

ICDDRB (2016). Health and demographic surveillance system - Matlab: Annual report (Scientific Report no. 138). ICDDRB.

Islam, M. M., \& Chuenpagdee, R. (2018). Nomadic fishers in the hilsa sanctuary of Bangladesh: The importance of social and cultural values for wellbeing and sustainability. In D. Johnson, T. Acott, N. Stacey, \& J. Urquhart (Eds.), Social wellbeing and the values of small-scale fisheries (pp. 195-216). Springer.

Ivey, P. (1993). Life-history theory perspectives on allocaretaking strategies among Efe foragers of the Ituri Forest of Zaire (Dissertation). University of New Mexico, Albuquerque, NM.

Ivey, P. (2000). Cooperative reproduction in the Ituri Forest hunter-gatherers: Who cares for Efe infants? Current Anthropology, 41, 856-866.

Jones, J. H., Bliege Bird, R., \& Bird, D. W. (2013). To kill a kangaroo: Understanding the decision to pursue high-risk/highgain resources. Proceedings of the Royal Society B: Biological Sciences, 280, 20131210. 
Kaplan, H. S., Hill, K., Lancaster, J. B., \& Hurdado, A. M. (2000). A theory of human life history evolution: Diet, intelligence, and longevity. Evolutionary Anthropology, 9, 156-185.

Konner, M. (2005). Hunter-gatherer infancy and childhood: The !Kung and others. In B. Hewlett \& M. Lamb (Eds.), Huntergatherer childhoods (pp. 19-64). Aldine.

Koster, J. (2011). On the analysis of risk-sensitive foraging: a comment on Codding et al. Proceedings of the Royal Society B: Biological Sciences, 278, 3171-3172.

Lehtonen, J., Parker, G. A., \& Scharer, L. (2016). Why anisogamy drives ancestral sex roles. Evolution, 70(5), $1129-1135$.

Levine, N. (1988). Women's work and infant feeding: A case from rural Nepal. Ethnology, 27(3), 231-251.

Livingston, G. (2014). Growing number of dads home with the kids: Biggest increase among those caring for family. Pew Research Center.

Marlowe, F. W. (2000). Paternal investment and the human mating system. Behavioral Processes, 51, 45-61.

Marlowe, F. W. (2007). Hunting and gathering: The human sexual division of foraging labor. Cross-Cultural Research, 41, 170-195.

Maxfield, S., Shapiro, M., Gupta, V., \& Hass, S. (2010). Gender and risk: Women, risk taking, and risk aversion. Gender in Management: An International Journal, 25, 586-604.

McElreath, R. (2020). Statistical rethinking: A Bayesian course with examples in $R$ and Stan, 2 nd ed. Taylor \& Francis.

McNamara, J. M., Szekely, T., Webb, J. N., \& Houston, A. I. (2000). A dynamic game-theoretic model of parental care. Journal of Theoretical Biology, 205, 605-623.

Meehan, C. L. (2008). Allomaternal investment and relational uncertainty among the Ngandu farmers of Central Africa. Human Nature, 19, 211-226.

Meehan, C. L. (2009). Maternal time allocation in two cooperative childrearing societies. Human Nature, 20, $375-393$.

Meehan, C. L., Helfrecht, C., \& Malcom, C. (2016). Implications of lengthy development and maternal life history: Allomaternal investment, peer relationships, and social networks. In C. L. Meehan \& A. Crittenden (Eds.), Childhood: Origin, evolution, and implications. University of New Mexico Press.

Milgram, B. L. (2001). Situating handicraft market women in Ifugao, Upland Philippines: A case for multiplicity. In L. J. Seligmann (Ed.), Women traders in cross-cultural perspective: Mediating identities, marketing wares. Stanford University Press.

Motee, A., Ramasawmy, D., Pugo-Gunsam, P., \& Jeewon, R. (2013). An assessment of the breastfeeding practices and infant feeding pattern among mothers in Mauritius. Journal of Nutrition and Metabolism, 2013, 1-8.

Murdock, G. P. (1949). Social structure. New York: Macmillan.

Murdock, G. P., \& Provost, C. (1973). Factors in the division of labor by sex: A cross-cultural analysis. Ethnology, $203-225$. OECD. (2017). The pursuit of gender equality: An uphill battle. Retrieved from https://doi.org/10.1787/9789264281318-en

Page, A. E., Viguier, S., Emmott, E., Dyble, M., Smith, D., \& Migliano, A. B. (2019, May 14). Grandmothers in the Agta: The role of demography and mobility. Presented at the Grandmothers and Public Health, London School of Hygiene and Tropical Medicine.

Panter-Brick, C. (1995). Child-care strategies in Nepal: Responses to ecology, demography, and society. In A. Boyce \& V. Reynolds (Eds.), Human populations: Diversity and adaptation. Oxford Science.

Phipps, S. A., \& Burton, P. S. (1998). What's mine is yours? The influence of male and female incomes on patterns of household expenditure. Economica, 65, 599-613.

Quinlan, R. J. (2003). Father absence, parental care, and female reproductive development. Evolution and Human Behavior, 24, 376-390.

Rahman, A., Mashreky, S., Chowdhury, S., Giashuddin, M., Uhaa, I., Shafinaz, S., ... Rahman, F. (2009). Analysis of the childhood fatal drowning situation in Bangladesh: Exploring prevention measures for low-income countries. Injury Prevention, 15, 75-79.

Schacht, R, \& Borgerhoff Mulder, M. (2015). Sex ratio effects on reproductive strategies in humans. Royal Society Open Science, 2, 140402.

Schacht, R, \& Kramer, K. L. (2016). Patterns of Family Formation in Response to Sex Ratio Variation. PLoS ONE, 11(8), e0160320. https://doi.org/10.1371/journal.pone.0160320.

Scharer, L., Rowe, L., \& Arnqvist, G. (2012). Anisogamy, chance and the evolution of sex roles. Trends in Ecology and Evolution, 27, 260-264.

Schubert, R., Brown, M., Gysler, M., \& Brachinger, H. W. (1999). Financial decision-making: Are women really more risk-averse? American Economic Review, 89(2), 381-385.

Schwartz, K., d'Arcy, H. J., Gillespie, B., Bobo, J., Longeway, M., \& Foxman, B. (2002). Factors associated with weaning in the first 3 months postpartum. The Journal of Family Practice, 51(5), 439-444.

Sear, R., \& Mace, R. (2008). Who keeps children alive? A review of the effects of kin on child survival. Evolution and Human Behavior, 29, 1-18.

Seligmann, L. J. (Ed.). (2001). Women traders in cross-cultural perspective: Mediating identities, marketing wares. Stanford University Press. 
Sellen, D. W. (2001). Weaning, complementary feeding, and maternal decision making in a rural East African pastoral population. Journal of Human Lactation, 17(3), 233-244.

Stan Development Team. (2018). R package version 2.17.3. Retrieved from http://mc-stan.org

Starkweather, K. E. (2017). Shodagor Family Strategies: Balancing work and family on the water. Human Nature, 28(2), $138-166$.

Trivers, R. (1972). Parental investment and sexual selection. In B. Campbell (Ed.), Sexual selection and the descent of man 1871-1971 (pp. 136-179). Aldine de Gruyter.

Tucker, B., Tsimitamby, Mr., Humber, F., Benbow, S., \& Iida, T. (2010). Foraging for development: A comparison of food insecurity, production, and risk among farmers, forest foragers, and marine foragers in Southwestern Madagascar. Human Organization, 69(4), 375-386.

Wasserstein, R. L, Schirm, A. L., \& Lazar, N. A. (2019). Moving to a world beyond ' $p<0.05$ '. The American Statistician, 73 (suppl. 1), 1-19.

Woodburn, J. (1982). Egalitarian societies. Man, 17(3), 431-451.

Cite this article: Starkweather KE, Shenk MK, McElreath R (2020). Biological constraints and socioecological influences on women's pursuit of risk and the sexual division of labour. Evolutionary Human Sciences 2, e59, 1-17. https://doi.org/10.1017/ ehs. 2020.60 